\title{
Sistem kompensasi dan kepuasan kerja guru tidak tetap di sebuah SMK Swasta di Indonesia
}

\section{(compensation system and job satisfaction of non-permanent private vocational high school teachers in indonesia)}

\author{
Yuni Listya Owada Siahaan', Rini Intansari Meilani ${ }^{2^{*}}$ \\ 1,2 Program Studi Pendidikan Manajemen Perkantoran \\ Fakultas Pendidikan Ekonomi dan Bisnis, Universitas Pendidikan Indonesia, \\ Jl. Dr. Setiabudhi, No. 229 Bandung, Jawa Barat Indonesia \\ Email: intanmusthafa@upi.edu
}

\begin{abstract}
ABSTRAK
Di Indonesia, keberadaan guru tidak tetap telah menjadibagian yang tidak terpisahkan dalam pencapain tujuan pendidikan nasional. Namun demikian, sistem kompensasi yang beragam dan belum baku bagi para guru tidak tetap di negara ini nampaknya berimbas pada ketidaktetapan jenis serta jumlah kompensasi yang mereka terima. Hal ini memicu tingginya tingkat ketidakpuasan mereka dalam bekerja dan belum optimalnya kualitas kerja mereka sebagai guru. Artikel ini membahas hasil penelitian yang ditujukan untuk mengetahui pengaruh sistem kompensasi bagi para guru tidak tetap di sebuah SMK Swasta di Jawa Barat terhadap kepuasan kerja mereka. Data diperoleh melalui angket yang disebarkan kepada 30 orang guru tidak tetap. Data yang terkumpul dianalisis secara deskriptif dan inferensial. Hasil penelitian menunjukkan sistem kompensasi berada pada kategori cukup efektif dan tingkat kepuasan kerja guru tidak tetap berada pada kategori rendah. Hal ini menunjukkan bahwa sistem kompensasi berpengaruh positif dan signifikan terhadap kepuasan kerja guru tidak tetap. Efektivitas sistem kompensasi bagi guru tidak tetap, khususnya jenis dan besaran insentif menjadi fokus utama yang harus ditingkatkan kualitasnya oleh sekolah dan pemerintah, berikut dengan peningkatan kualitas aspek psikologis dalam hal penciptaan lingkungan yang mendukung para guru tidak tetap agar merasa nyaman dan betah untuk terus bekerja.
\end{abstract}

Kata Kunci: Kepuasan Kerja; Sistem Kompensasi

\begin{abstract}
In Indonesia, the existence of non-permanent teachers has become an inseparable part of achieving national education goals. However, a diverse and non-standard compensation system for non-permanent teachers in this country seems to have an impact on the types and amounts of compensation they receive. This triggers, in general, the high level of dissatisfaction in their work and the lack of optimal quality of their work as teachers. This article discusses the results of research aimed at knowing the effect of compensation systems for non-permanent teachers, of a private vocational high school in West Java, on their job satisfaction. Data was
\end{abstract}

Received: Februari 2019, Revision: Mei 2019, Published: Juli 2019 
obtained through questionnaires distributed to 30 non-permanent teachers. Collected data were analyzed descriptively and inferentially. The results showed that the compensation system was in the category of being quite effective and the level of teacher jobsatisfaction was in low category. This shows that the compensation system has a positive and significant effect on non-permanent teachers' job satisfaction. The effectiveness of the compensation system for nonpermanent teachers, especially the type and amount of incentives, is the main focus that must be improved by schools' authority and the government, along with the improvement of the quality of psychological aspects, especially in terms of creating an environment that supports non-permanent teachers to feel comfortable and be willing to continue working.

Keywords: Job Satisfaction; Compensation System; Non-Permanent Teachers; Vocational High School in Indonesia

\section{PENDAHULUAN}

Pada setiap organisasi, baik laba maupun nirlaba, karyawan memiliki peran yang sangat penting yang berpengaruh terhadap pencapaian tujuan organisasi secara umum. Sama hal nya dengan karyawan, guru yang merupakan pekerja pada organisasi sekolah juga memiliki peran yang tidak sedikit terhadap kualitas peserta didik, sekolah, dan kualitas pendidikan secara nasional, bahkan internasional. Layaknya karyawan yang bekerja di perusahaan, kesejahteraan guru pun penting untuk diperhatikan.

Di Indonesia, ada beragam jenis guru, salah satuya adalah guru tidak tetap (GTT). Secara umum, kesejahteraan guru tidak tetap sangat mengkhawatirkan, karena sistem kompensasi yang mereka terima belum memiliki standar yang jelas di setiap sekolah, baik dari jenisnya, jumlah jenisnya, besarannya, dan pendistribusiannya. Hal ini tentu akan berdampak pada tingkat kepuasan kerja dan kinerja mereka, dan berimbas pada kualitas peserta didik mereka, sekolah, dan masyarakat secara umum. Seperti yang disampaikan oleh Zubr, Sokolová, \& Mohelská (2016), bahwa salah satu pilar keberhasilan sebuah organisasi itu ditentukan oleh keberadaan karyawan yang puas dengan pekerjaanya, karena karyawan yang puas dengan pekerjaannya memiliki tingkat produktivitas kerja yang tinggi. Selain produktifitas yang tinggi, Moorhead \& Griffin (2013) mengatakan karyawan yang puas dengan pekerjaannya cenderung memiliki dedikasi yang tinggi terhadap tempat kerjanya. Lebih lanjut mereka menjelaskan bahwa empat karakteristik karyawan yang memiliki tingkat kepuasan kerja yang tinggi adalah tingginya tingkat kehadiran mereka (jarang absen), memberikan kontribusi yang positif tehadap tempat kerjanya, betah bersama dengan organisasi (tumbuh dan belajar bersama organisasi), dan senang dengan pekerjaanya (memiliki tingkat stress kerja yang rendah).

Dari penjelasan di atas, jelas sekali bahwa kepuasan kerja karyawan sangat penting untuk diperhatikan dan diusahakan pencapainnya. Ketika karywan tidak puas dengan pekerjaanya, maka akan sulit bagi organisasi untuk mencapai tujuannya, dan beragam hal yang tidak diharapkan dapat terjadi.

Salah satu potret ketidakpuasan guru tidak tetap terhadap sistem kompensasi sekolah terdapat di salah satu Sekolah Menengah Kejuruan (SMK) swasta di provinsi Jawa Barat. Berdasarkan pengumpulan informasi di lapangan, dalam rentang waktu tiga tahun, sekolah tersebut tidak memberikan peningkatan kompensasi. Misalnya, tidak ada insentif hari raya, tidak ada biaya penggantian untuk pengembangan materi ajar dan media pembelajaran, dan tidak ada penggantian alat praktek yang digunakan guru tidak tetap-padahal, fasilitas mengajar di SMK tersebut kurang memadai. Bahkan, jika dibandingkan dengan SMK swasta lain yang sederajat dan berada di sekitarnya, SMK 
swasta tersebut memiliki sistem kompensasi yang perlu diperbaiki. Hal tersebut nampaknya berimbas terhadap kepuasan kerja para GTT yang terus menurun. Salah satu indikatornya adalah tingkat ketidakhadiran guru tidak tetap yang terus meningkat dalam rentang waktu tersebut, seperti terlihat pada tabel berikut.

\section{Tabel 1}

Presensi Guru Tidak Tetap (GTT) tahun 2015-2018

\begin{tabular}{|c|c|c|c|}
\hline Tahun & $\begin{array}{c}\text { Jumlah } \\
\text { GTT }\end{array}$ & $\begin{array}{c}\text { Persentase Kehadiran } \\
\mathbf{( \% )}\end{array}$ & $\begin{array}{c}\text { Persentase } \\
\text { Ketidak-hadiran (\%) }\end{array}$ \\
\hline $2015 / 2016$ & $\mathbf{3 5}$ & 77,08 & 22,92 \\
\hline $2016 / 2017$ & $\mathbf{3 3}$ & 75,32 & 24,68 \\
\hline $2017 / 2018$ & $\mathbf{3 0}$ & 73,92 & 26,02 \\
\hline
\end{tabular}

Sistem kompensasi yang berlaku di sebuah organisasi memiliki peran yang sangat penting karena merupakan salah satu aspek paling sensitif. Secara umum, hal-hal yang seringkali dikeluhkan oleh karyawan sebagai bentuk ketidakpuasan terhadap pekerjaan mereka meliputi permasalahan yang berkaitan dengan gaji (salah satu jenis kompensasi), keselamatan kerja, kesulitan kerja, kemampuan menyelesaikan masalah kerja, dan peluang untuk mendapatkan promosi. Padahal, seperti yang ditegaskan oleh Inuwa (2016), organisasi, baik sektor swasta maupun sektor pemerintahan, di seluruh dunia, bergantung pada produktivitas optimal para karyawan yang mereka miliki karena pada gilirannya hal tersebut berrkaitan erat dengan pencapaian efektivitas organisasi. Maka dari itu, beliau menjelaskan bahwa memastikan kepuasan kerja para karyawan adalah hal yang wajib dilakukan oleh setiap organisasi. Lebih lanjut dikatakan bahwa walaupun telah banyak studi yang dilakukan oleh para peneliti sekaitan dengan hal tersebut, diperlukan studi yang lebih banyak lagi pada bidang kajian ini karena karyawan adalah bagian yang tidak terpisahkan dari sebuh organisasi. Hal serupa pun disampaikan oleh Kelechi et al. (2016) yang mengatakan bahwa penelitian yang mengkajisistemkompensasi harus terus dilakukan pada organisasi swasta maupun pemerintah, untuk dapat benar-benar memahami system kompensasi secara mendalam. Maka dari itu, penulis melakukan penelitian yang ditujukan untuk memotret serta mengetahui keterkaitan antara sistem kompensasi dan kepuasan kerja, dengan konteks penelitian yang difokuskan pada para GTT di sebuah SMK swasta.

\section{TINJAUAN PUSTAKA}

\section{Sistem Kompensasi}

Al-nasser (2016) mengatakan bahwa sistem kompensasi adalah bagian fundamental dari hubungan yang tercipta diantara organisasi dengan para karyawannya. Sebagai sebuah sistem, pembayaran kompensasi memiliki fungsi startegik yang memberikan impak signifikan pada fungsi sumber daya manusia dalam sebuah organisasi (Silaban \& Syah, 2018).

Dalam konteks sekolah, kompensasi yang diterima oleh guru dapat mempengaruhi fungsi dan tanggungjawab guru, karena kompensasi yang diterima berpengaruh kepada fisik dan mental mereka. Maka dari itu, guru harus mendapatkan kompensasi yang layak karena hal tersebut akan mendorong guru dalam bekerja, mereka akan lebih semangat dan produktif, serta memberikan pekerjaan yang terbaik dan mengerahkan seluruh kemampuannya dalam bekerja di sekolah. Pemberian kompensasi haruslah proporsional sesuai dengan beban kerja yang dimilki oleh guru, seperti yang disampaikan oleh Khan, 
Khan, Kundi, \& Nawaz (2014) bahwa kompensasi yang tepat akan mendorong karyawan untuk bekerja lebih baik dan lebih nyaman untuk mencapai tujuan organisasi

Kompensasi pada dasarnya adalah semua manfaat yang diberikan kepada karyawan sebagai imbalan dari layanan yang diberikan oleh karyawan (Choudhary, 2016). Choudary menjelaskan bahwa karyawan saat ini tidak hanya membutuhkan uang untuk memenuhi kebutuhan dasar mereka, tetapi mereka juga memerlukan berbagai imbalan non finansial serta manfaat, yang sering dikenal sebagai tunjangan (Fringe Benefits), yang diantaranya terdiri dari bonus, tunjangan pensiun, hadiah, pendidikan, fasilitas medis, dan lain sebagainya. Kompensasi yang diberikan kepada karyawan sedapat mungkin harus dapat memuaskan mereka, sehingga mereka menghargai profesi mereka, termotivasi untuk meningkatkan performa kerja mereka dan mempertahankan pekerjaan mereka di organisasi, karena kompensasi secara langsung atau tidak langsung mempengaruhi kinerja karyawan.

Menurut Adeoye (2014), kompensasi terdiri atas 4 bentuk, antara lain:

a) Upah dan Gaji: Upah adalah apa yang dibayarkan kepada karyawan yang tidak dipekerjakan secara permanen dan biasanya berkaitan dengan tarif pembayaran per jam (semakin banyak jam kerja, semakin besar bayarannya), sementara gaji adalah apa yang dibayarkan kepada orangorang yang dipekerjakan secara permanen dan ini pada tingkat upah tetap mingguan, bulanan, atau tahunan

b) Insentif: Ini adalah kompensasi tambahan yang besarannya di atas dan melampaui upah karyawan atau gaji yang diberikan, bisa bersifat jangka panjang atau jangka pendek.

c) Tunjangan Karyawan: cuti berbayar, tunjangan pensiun, penggantian biaya sekolah, kegiatan rekreasi, dan uang makan.

d) Hak Istimewa Tambahan: Karyawan dalam organisasi dapat memiliki hak istimewa lainnya seperti penggunaan kendaraan / mobil perusahaan, keanggotaan klub, atau tunjangan perjalanan.

Semua bentuk kompensasi ini, menurut Salisu, Chinyio, \& Suresh (2015), adalah sebuah bentuk penghargaan bagi karyawan karena mereka telah berkontribusi dalam pencapaian segala tujuan dari tempat mereka bekerja. Maka dari itu, sistem kompensasi harus dirancang dan dilaksanakan dengan baik, dan seperti yang diungkapkan Szymendera (2017) pemimpin perusahaan adalah pihak yang memiliki wewenang untuk mewujudkan sistem kompensasi yang layak dan menjamin semua pembiayaan tersebut. Dalam penelitian yang dilakukan oleh OO, AE, \& OE (2016), diperoleh temuan yang menegaskan betapa pentingnya bagi organisasi untuk memiliki desain paket kompensasi yang memadai bagi karyawan. Mereka mengutarakan bahwa kompensasi memilikiperan khusus bagi pegawai terutama dalam pembentukan komitmen pegawai dalam bekerja. Dalam penelitian yang dilakukan, merekamenyimpulkan bahwa kompensasi memiliki pengaruh yang signifikan dan positif terhadap komitmen organisasi dan kinerja para karyawan.

Hasil penelitian yang serupa pun dikemukakan oleh Kelechi et al. (2016) dimana mereka menemukan bahwa sistem kompensasi berpengaruh secara positif terhadap produktifitas pegawai. Mereka pun menyarankan agar pimpinan organisasi secara berkelanjutan mengembangkan prosedur pemberian kompensasi yang akan membantu mereka untuk menarik, memotivasi, mempertahankan, dan meuaskan para karyawannya. Selain pimpinan organisasi, peran pemerintah pun sangatlah penting. Seperti yang dilaporkan Inuwa (2016) bahwa kurangnya pendanaan dari pemerintah, berupa skala gaji yang kecil serta pembayaran gaji yang tidak tepat waktu dan tidak 
konsisten, dan pembedaan gaji bagi guru dengan status yang berbeda juga telah menyebabkan ketidakpuasan kerja yang cenderung menurunkan kinerja guru secara keseluruhan.

Dari paparan di atas, dapat disimpulkan bahwa sistem kompensasi memiliki pengaruh bukan hanya terhadap kepuasan kerja pegawai dalam bentuk peningkatan motivasi, dedikasi dan komitmen kerja pegawai tetapi juga terhadap produktifitas dan efektifitas kerja pegawai dan organisasi secara keseluruhan.

\section{Kepuasan Kerja}

Menurut Msuya (2016), kepuasan kerja merupakan elemen penting dalam menjaga kualitas sumber daya manusia dan kehidupan setiap organisasi. Mereka mengatakan bahwa dalam dunia akademis, khususnya sekolah menengah, kepuasan kerja karyawan adalah salah satu pilar penting dari sekolah menengah yang lebih sehat. Namun demikian, beberapa penelitian sebelumnya menemukan bahwa pada konteks pendidikan, banyak ditemukan guru yang tidak puas dengan pekerjaaanya dan menyebabkan tingkat turnover mereka cukup tinggi, yang merupakan kemunduran bagi kualitas sekolah (Jha, 2014:3). Misalnya adalah sebuah studi yang dilakukan oleh Weldeyohannes (2016) yang menunjukkan bahwa secara umum guru sangat tidak puas dengan sistem kompensasi yang diterapkan sekolah, baik secara finansial/non-finansial. Mereka menemukan bahwa ketidakpuasan para guru tersebut menyebabkan pergeseran kualifikasi yang menyebabkan mereka tidak meningkatkan kualifikasi sebelumnya secara vertikal dan berniat melakukan turnover atau pengunduran diri. Penelitian ini merekomendasikan perlunya meninjau kembali kompensasi guru yang diberikan agar sepadan dengan beban kerja yang mereka lakukan. Temuan penelitian ini dapat membantu para perencana pendidikan dalam menyiapkan kebijakan serta merancang prosedur pendistribusian kompensasi sehingga memungkinkan guru untuk mencintai, mempertahankan dan meningkatkan kualitas kerja mereka.

Ada beberapa hal yang dapat dilakukan untuk mengetahui tingkat kepuasan guru terhadap pekerjaanya. Shooshtarian, Ameli, \& Aminilari (2013) mengungkapkan bahwa kepuasan kerja terdiri dari sikap karyawan tentang promosi, pengawas, pekerjaan, gaji, kompensasi dan kemampuan beradaptasi dengan situasi kerja. Hal ini dapat menjadi dasar atas kepuasan kerja guru tidak tetap selama mereka bekerja di sebuah sekolah.

Hajdukova, Klementova, \& Klementova jr (2015) mengungkapkan bahwa penilaian terhadap kondisi kerja seorang pegawai tercermin pada sikap yang dia miliki terhadap kepuasan kerjanya. Untuk mengetahui tingkat kepuasan kerja karyawan, perlu dibedakan apakah seseorang benar-benar puas di tempat kerja, atau hanya dipuaskan oleh beberapa factor saj, sejauh mana berbagai aspek pekerjaan penting tersebut berefek bagi kepuasan kerjanya (intensitas) saat ini, dan untuk mengenali pada saat kapankah pegawai ini merasa puas dengan pekerjaannya dan kapan tidak merasa puas. Setiappegawai tidak hanya berpikir untuk melakukan yang terbaik bagi tempat kerjanya, tapi juga mengharapkan imbalan atas pekerjaannya, dan jika remunerasi atas pekerjaanya tidak terpenuhi melalui system kompensasi yang baik, maka kecenderungannya mereka akanberhenti dan mencari pekerjaan lain. Hal ini juga berlaku bagi guru, semakin rendah tingkat kepuasannya maka ia akan mencari pekerjaan lain. Hal yang sering terjadi adalah pengunduran diri, dan tak jarang sekolah tidak melakukan perbaikan terhadap system kompensasi mereka. Bagi sekolah, kepuasan kerja guru hanya berdampak pada diri guru itu sendiri padahal kepuasan kerja guru khususnya GTT juga sangat penting untuk siswa dan sekolah mereka. Karena GTT yang

Copyright (c) 2019, EISSN 2656-4734 
puas dengan pekerjaanya secara normative akan memiliki tingkat kehadiran yang tinggi serta motivasi dan kualitas kerja yang lebih baik (You, Kim, \& Lim, 2015).

Menurut Raziq \& Maulabakhsh (2015), untuk meningkatkan kepuasan karyawan yang bekerja di bawah kondisi kerja yang sulit, manajemen, dalam hal ini sekolah, perlu memperbaiki kondisi kerja. Hal tersebut akan membuat para guru merasa sama puasnya dengan mereka yang bekerja dalam kondisi kerja normal, dan timbal baliknya adalah mereka akan meningkatkan kualitas kerja mereka. Seperti yang disampaikan oleh Bakotić (2016) bahwa "pegawai yang memiliki tingkat kepuasan kerja tinggi umumnya menyukai pekerjaan mereka; mereka merasakan keadilan di lingkungan tempat mereka bekerja, dan merasa bahwa pekerjaan mereka memberi mereka beberapa fitur positif seperti keragaman, tantangan, gaji dan keamanan yang baik, otonomi, rekan kerja yang menyenangkan, dll. Pekerja yang senang bekerja bahkan akan menggunakan waktu pribadi untuk kegiatan kerja mereka, mereka akan menjadi kreatif dan berkomitmen, mereka akan mencari cara untuk mengatasi hambatan apa pun yang mungkin ada dalam realisasi pekerjaan mereka, dan mereka akan membantu rekan dan atasan mereka. Para pekerja ini akan memiliki kinerja luar biasa, dan perusahaan-perusahaan dengan jenis pekerja ini akan berhasil".

\section{METODE PENELITIAN}

Untuk mencapai tujuan penelitian yang dilakukan oleh penulis, penelitian dilakukan dengan menerapkan pendekatan penelitian kuantitatif, khususnya desain penelitian survey. Data pada penelitian ini diperoleh melalui penyebaran angket yang ditujukan untuk mengetahui persepsi 30 GTT (yang merupakan populasi dalam penelitian ini) mengenai sistem kompensasi di tempat mereka bekerja dan mengenai kepuasan kerja mereka dengan sistem kompensasi yang diterapkan. Analisis statistik deskriptif berupa penghitungan frekuensi dilakukan untuk mengetahui gambaran jawaban para responden mengenai kedua variabel yang diteliti dalam penelitian ini. Dan analisis regresi sederhana dilakukan untuk mengetahui seberapa besar pengaruh tingkat efektivitas sistem kompensasi terhadap tingkat kepuasan kerja para GTT.

\section{HASIL PENELITIAN \\ Sistem Kompensasi}

Hasil pengolahan data terhadap variabel sistem kompensasi diperoleh kesimpulan bahwa tingkat efektivitas sistem kompensasi berada pada kategori cukup efektif. Hal tersebut ditunjukkan oleh besarnya persentase tanggapan responden terhadap pernyataan kurang setuju, yaitu 32\%, sebagaimana ditunjukan oleh tabel berikut:

Tabel 2

Presenatse Variabel Sistem Kompensasi

\begin{tabular}{|l|l|c|c|}
\hline \multicolumn{1}{|c|}{ Kategori } & \multicolumn{1}{c|}{ Sistem Kompensasi } & Frekuensi (F) & Persentase (\%) \\
\hline Sangat Setuju & Sangat Efektif & 9 & $3 \%$ \\
\hline Setuju & Efektif & 73 & $24 \%$ \\
\hline Kurang Setuju & Cukup Efektif & 95 & $32 \%$ \\
\hline Ragu-ragu & Kurang Efektif & 81 & $27 \%$ \\
\hline Tidak Setuju & Tidak Efektif & 42 & $14 \%$ \\
\hline
\end{tabular}

Adapun indikator tertinggi dalam variabel sistem kompensasi ini adalah indikator gaji dengan presentase sebesar 50,35\% dan indikator terendah adalah insentif dengan presentase sebesar $49,65 \%$, seperti terlihat pada tabel berikut: 
Tabel 3

Presentase Indikator Variabel Sistem Kompensasi

\begin{tabular}{|c|c|c|c|}
\hline No. & Indikator & Presentase & Kategori \\
\hline 1 & Gaji & $50,35 \%$ & Sedang/Cukup Efektif \\
\hline 2 & Insentif & $49,65 \%$ & Sedang/Cukup Efektif \\
\hline
\end{tabular}

\section{Kepuasan Kerja}

Adapun sekaitan dengan tingkat kepuasankerja GTT, hasil analisis data menunjukan bahwa variabel ini berada pada kategori rendah, karena mayoritas GTT menjawab ragu-ragu ketika diberikan pertanyaan sekaitan tingkat kepuasan kerja mereka (45\%), sebagaimana ditunjukan oleh tabel berikut. Halini menunjukan bahwa hamper setengah daripopulasi GTT yang dilibatkan dalm studi ini menilai bahwa system kompensasi yang mereka terima jauh dari memuaskan.

\section{Tabel 4}

Presentase Variabel Kepuasan Kerja

\begin{tabular}{|l|l|c|c|}
\hline \multicolumn{1}{|c|}{ Kategori } & \multicolumn{1}{c|}{ Kepuasan Kerja GTT } & Frekuensi (F) & Persentase (\%) \\
\hline Sangat Setuju & Sangat Tinggi & 12 & $3 \%$ \\
\hline Setuju & Tinggi & 41 & $10 \%$ \\
\hline Kurang Setuju & Cukup & 114 & $27 \%$ \\
\hline Ragu-ragu & Rendah & 188 & $45 \%$ \\
\hline Tidak Setuju & Sangat Rendah & 65 & $15 \%$ \\
\hline
\end{tabular}

Adapun indikator tertinggi dalam variabel kepuasan kerja, seperti terlihat pada tabel di bawah ini, adalah indikator tingkat stress rendah. Sementara indikator terendah adalah indikator betah bersama organisasi. Hal ini menunjukkan bahwa kurang dari seperempat dari total populasi guru yang dilibatkan dalam studi ini yang merasa betah bekerja di tempat mereka ini.

Tabel. 5

Presentase Indikator Variabel Kepuasan Kerja

\begin{tabular}{|c|l|c|c|}
\hline No & \multicolumn{1}{|c|}{ Indikator } & Presentase & Kategori \\
\hline 1 & Jarang Absen & $24 \%$ & Ragu-ragu/Rendah \\
\hline 2 & Memberikan Kontribusi Positif & $25 \%$ & Ragu-ragu/Rendah \\
\hline 3 & Betah Bersama Organisasi & $23 \%$ & Kurang Setuju/Cukup \\
\hline 4 & Tingkat Stress Rendah & $29 \%$ & Kurang Setuju/Cukup \\
\hline
\end{tabular}

\section{Pengaruh Sistem Kompensasi terhadap Kepuasan Kerja GTT}

Berdasarkan hasil analisis statistik inferensial dengan menggunakan perhitungan analisis regresi sederhana, diperoleh persamaan regresi $\hat{Y}=1147.18397+0.7741$. Tanda (+) di depan angka 0.7741 menunjukkan hubungan antara variabel bebas (sistem kompensasi) dan variabel terikat (kepuasan kerja) berjalan satu arah. Jika variabel sistem kompensasi meningkat, maka variabel kepuasan kerja GTT juga akan meningkat begitupun sebaliknya.

Berdasarkan perhitungan pengujian hipotesis diperoleh $\mathrm{F}_{\text {hitung }}>\mathrm{F}_{\text {Tabel }}$ yaitu 9.0820, sedangkan $\mathrm{F}_{\text {tabel }}$ dengan tingkat kesalahan $\alpha=0,05$ dan dan dk reg b/a $=1$ dan $\mathrm{dk}$ res $=\mathrm{n}-2=28$ sebesar $\mathbf{4 2 1 0 0 0 8 4 . 3 5 4 1}$, artinya $F_{\text {hitung }}>F_{\text {tabel }}$ yaitu yaitu 9.0820 > 4.2100. Dapat disimpulkan bahwa "terdapat pengaruh positif dan signifikan dari sistem kompensasi terhadap kepuasan kerja GTT". Nilai koefisien determinasi variabel disiplin kerja dan variabel efektivitas kerja guru sebesar $40.22 \%$ pun menunjukkan bahwa 
secara parsial system kompensasi memiliki dampak terhadap kepuasan kerja sebesar 40.22\%. Sisanya sebesar $59.78 \%$ dipengaruhi oleh faktor lain yang mempengaruhi kepuasan kerja GTT.

\section{KESIMPULAN}

Berdasarkan hasil penelitian yang telah dengan tujuan untuk mengetahui pengaruh sistem kompensasi terhadap kepuasan kerja guru tidak tetap, dapat ditarik kesimpulan bahwa: (1) tingkat efektivitas sistem kompensasi di SMK swasta yang diteliti berada pada kategori cukup efektif, (2) tingkat kepuasan guru tidak tetap di SMK tersebut menunjukkan bahwa kepuasan guru tidak tetap berada pada kategori rendah, dan (3) terdapat pengaruh positif dan signifikan dari sistem kompensasi terhadap tingkat kepuasan kerja guru tidak tetap.

\section{Saran}

1. Semua indikator dalam variable sistem kompensasi sudah semestinya diperhatikan dengan baik oleh pihak sekolah, khususnya dalam kaitannya dengan sistem kompensasi yang diterapkan bagi GTT. Sebagai tenaga pendidik yang membimbing para siswa sebagai generasi penerus bangsa, sudah selayaknya mereka mendapatkan kompensasi yang seimbang dengan guru tetap, walau tentunya disesuaikan dengan beban kerja yang mereka miliki. Peningkatan kualita sistem kompensasi ini pun sudah seharusnya diperhatikan juga oleh pemerintah, terutama mengingat jumlah GTT yang tidak sedikit di Indonesia. Dengan sistem insentif yang baik, dan tentunya sistem gaji yang mencukupi, kinerja guru tidak tetap secara relatif akan meningkat, karena asumsinya jika jumlah insentif sesuai dengan capaian kerja yang dilakukan, sesuai dengan kegiatan administrasi yang dilakukan, pemberiannya tepat waktu, sesuai dengan prestasi kerja yang dilakukan maka kinerja mereka akan meningkat, dan imbasnya adalah pada peningkatan kualitas siswa dan sekolah secara umum.

2. Sekaitan dengan variabel kepuasan kerja, indikator yang harus ditingkatkan adalah indikator betah bersama organisasi. Sebagai salah satu faktor psikologis, untuk meningkatkan rasa betah bekerja ini dapat dilakukan melalui beberapa hal. Selain perbaikan sistem kompensasi, hal yang sebaiknya dilakukan oleh pihak sekolah adalah dengan melengkapi semua kebutuhan dasar yang mendukung proses pembelajaran di kelas, adanya sistem penggantian untuk setiap media atau alat bantu pembelajaran yang dibuat atau diusahakan oleh para GTT, serta dilibatkannya mereka dalam kegiatan kekeluargaan atau non-kurikuler di sekolah yang akan mengakrabkan mereka dengan pihak sekolah yang imbasnya diharapkan berupa kenyamanan dan kebetahan para GTT untuk terus bekerja di sekolah dimana mereka mengajar.

\section{DAFTAR PUSTAKA}

Adeoye, A. O. (2014). The Influence of Compensation Management on Employee' s Leadership Role in Insurance Sector: Nigeria Experience The Influence of Compensation Management on Employee' s Leadership Role in Insurance Sector : Nigeria Experience. Mediterranean Journal of Social Sciences, 5(27), 342-352. https://doi.org/10.5901/mjss.2014.v5n27p342

Al-nasser, A. (2016). The Effective Compensation System in Organizations. IOSR Journal of Business and Management, 18(11), 85-88. https://doi.org/10.9790/487X-1811048588

Bakotić, D. (2016). Relationship between Job Satisfaction and Organisational 
Performance. Economic Research-Ekonomska Istraživanja, 29(1), 118-130. https://doi.org/10.1080/1331677X.2016.1163946

Choudhary, S. (2016). Theoretical Perspective of Compensation Management in Organizations. International Journal of Multidisciplinary Research and Development, 3(10), 77-80.

Hajdukova, A., Klementova, J., \& Klementova jr, J. (2015). The Job Satisfaction as a Regulator of the Working Behaviour. Procedia - Social and Behavioral Sciences, 190, 471-476. https://doi.org/10.1016/j.sbspro.2015.05.028

Inuwa, M. (2016). Job Satisfaction and Employee Performance: An Empirical Approach. The Millennium University Journal, 1(1), 90-103.

Kelechi, N. G., VO, A., TK, E., AA, A., AO, S., \& AE, H. (2016). The Effect of Compensation Administration on Employee Productivity. Arabian Journal of Business and Management Review, 5(8), 40-47. https://doi.org/10.12816/0027245

Khan, M. S., Khan, I. U., Kundi, G. M., \& Nawaz, A. (2014). The Impact of Job Satisfaction and Organizational Commitment on the Intention to Leave among the Academicians. International Journal of Academic Research in Business and Social Sciences, 4(2), 114-131. https://doi.org/10.6007/IJARBSS/v4-i2/610

Moorhead, G., \& Griffin, R.W. (2013). Perilaku Organisasi:Manajemen Sumber Daya Manusia dan Organisasi, Edisi 9, Jakarta: Salemba Empat.

Msuya, O. W. (2016). Exploring Levels of Job Satisfaction Among Teachers in Public Secondary Schools in Tanzania. International Journal of Educational Administration and Policy Studies, 8(2), 9-16.

OO, O., AE, O., \& OE, F. (2016). Empirical Appraisal of Compensation and Organizational Commitment in Education Management. Mediterranean Journal of Social Sciences, 7(3), 296-301. https://doi.org/10.5901/mjss.2016.v7n3p296

Raziq, A., \& Maulabakhsh, R. (2015). The Impact of Working Environment on Job Satisfaction. Procedia Economics and Finance, 23, 717-725. https://doi.org/10.1016/S2212-5671(15)00524-9

Salisu, J. B., Chinyio, E., \& Suresh, S. (2015). The Impact of Compensation on the Job Satisfaction of Public Sector Construction Workers of Jigawa State of Nigeria. The Business and Management Review, 6(4), 282-296.

Shooshtarian, Z., Ameli, F., \& Aminilari, M. (2013). The Effect of Labor's Emotional Intelligence on Their Job Satisfaction, Job Performance and Commitment. Iranian Jurnal of Management Studies (IJMS), 6(1), 29-45.

Silaban, N., \& Syah, T. Y. R. (2018). The Influence of Compensation and Organizational Commitment on Employees' Turnover Intention. IOSR Journal of Business and Management, 20(3), 1-6. https://doi.org/10.9790/487X-2003010106

Szymendera, S. D. (2017). Workers 'Compensation: Overview and Issues.

Weldeyohannes, G. (2016). Compensation Practice and Teachers Turnover Intention in Tigray. International Journal of Science and Research (IJSR), 5(9), 1372-1379.

You, S., Kim, A. Y., \& Lim, S. A. (2015). Job Satisfaction Among Secondary Teachers in Korea: Effects of Teachers' Sense of Efficacy and School Culture. Educational Management Administration \& Leadership, 1-14. https://doi.org/10.1177/1741143215587311

Zubr, V., Sokolová, M., \& Mohelská, H. (2016). The Influence of Selected Factors on Overall Job Satisfaction. Littera Scripta, 9(2), 169-184. 